\section{BMJ Paediatrics Open}

\title{
What families in the UK use to manage attention-deficit/hyperactivity disorder (ADHD): a survey of resource use
}

\author{
Philippa Fibert (iD , ${ }^{1}$ Clare Relton ${ }^{2}$
}

To cite: Fibert P, Relton C. What families in the UK use to manage attention-deficit/ hyperactivity disorder (ADHD): a survey of resource use. BMJ Paediatrics Open 2020;4:e000771. doi:10.1136/ bmjpo-2020-000771

- Additional material is published online only. To view, please visit the journal online (http://dx.doi.org/10.1136/ bmjpo-2020-000771).

Received 26 June 2020 Revised 13 October 2020 Accepted 15 October 2020
Check for updates

(c) Author(s) (or their employer(s)) 2020. Re-use permitted under CC BY-NC. No commercial re-use. See rights and permissions. Published by BMJ.

${ }^{1}$ Health Hawk, High Wycombe, UK

${ }^{2}$ Institute of Population Health, Queen Mary University of London, London, UK

Correspondence to Dr Philippa Fibert; philippafibert@gmail.com

\section{ABSTRACT}

Objective To identify interventions being used to manage attention-deficit/hyperactivity disorder (ADHD) in the UK.

Design A survey within the Sheffield Treatments for ADHD Research project. A convenience sample of participants in the UK who consented to join an observational cohort were asked closed questions about medication, behavioural change programmes and service use, and an open-ended question about what else they used.

Setting A broad variety of non-National Health Service, non-treatment seeking settings throughout the UK, including local authority organisations, schools, ADHD and autism spectrum condition support groups and social media.

Participants Families of children aged 5-18 with carer reported ADHD and Conners Global Index (CGI) T scores of $55+$.

Results Responses from 175 families were analysed. The mean age of the children was 10.21 (2.44), and twothirds $(n=114)$ had additional diagnoses. The majority used medications to manage $\operatorname{ADHD}(n=120)$ and had participated in a parenting class $(n=130)$. Just over a quarter $(28 \%, \mathrm{n}=49)$ did not use ADHD medications, and used sleep medications. Just under half had consulted psychologists ( $\mathrm{n}=83$ ), and 32 had participated in other talking therapies such as psychotherapy, counselling and cognitive-behavioural therapy. A few used aids such as reward charts or fiddle toys $(n=17)$ and participated in activities (mostly physical) $(n=14)$. A substantial minority (78/175) had used non-mainstream treatments, the most popular being homoeopathy $(n=32)$, nutritional interventions $(n=21)$ and bodywork such as massage or cranial osteopathy $(n=9)$.

Conclusions Families reported use of a wide variety of treatments to help with management of their children with $\mathrm{ADHD}$ in addition to their use of mainstream treatments.

\section{INTRODUCTION}

Attention-deficit/hyperactivity disorder (ADHD) is one of the most commonly diagnosed and treated childhood psychiatric disorders. Children are hyperactive (fidgety and unable to sit still for long periods), and impulsive (doing things without stopping to think). They find it hard to concentrate and follow instructions, and to regulate their emotions. This results in problems at school, at home, and with their peers where

\section{What is known about the subject?}

For many of those with attention-deficit/hyperactivity disorder (ADHD) mainstream interventions do not improve long-term outcomes.

- Carers additionally try non-mainstream interventions to help their children.

- Surveys documenting what carers try have been conducted in a variety of countries but not in the UK.

\section{What this study adds?}

Families with children with ADHD in the UK are using a wide variety of main and non-mainstream treatments, which are both publicly and privately funded, to help with ADHD management.

- Nearly $70 \%$ of those surveyed reported using pharmaceutical medications, $74 \%$ had participated in a parenting class, and $45 \%$ reported use of nonmainstream treatments.

- The most popular non-mainstream treatments used were nutrition, homoeopathy, massage and cranial osteopathy.

they struggle to fit in, ${ }^{1}$ and get into trouble. ${ }^{2}$ Heterogeneity (non-uniformity) is a feature of ADHD expression. Children often have a wide range of other diagnoses and co-occurring problems such as autism spectrum conditions (ASCs) $(50 \%-75 \%),{ }^{3}$ conduct disorders $(24 \%),{ }^{4}$ sleep disorders $(25 \%-50 \%),{ }^{5}$ tics $(60 \%),{ }^{6}$ gut dysbiosis, ${ }^{7}$ obesity $(40 \%),{ }^{8}$ anxiety, depression $(33 \%),{ }^{9}$ reading and other learning problems. ${ }^{10}$

Treating ADHD is challenging. Interventions are offered to help manage symptoms. The National Health Service (NHS) offers National Institute for Health and Care Excellence (NICE) recommended treatments of behaviour change programmes and pharmaceutical medications. Recent NICE updates suggest also asking about diet and offering advice if relevant. While implemented, recommended treatments often palliate some symptoms making classroom and family life more 
manageable, however, their long-term effectiveness and ability to address important negative outcomes remains in doubt. ${ }^{11}$ Adherence is poor and side effects of pharmaceutical medications common. ${ }^{12}$

While the majority of carers of children with ADHD in the UK rely on NICE recommended treatments, a number try other treatments, identified by themselves rather than doctor recommendation, and usually requiring out of pocket payments. Such treatments are collectively described in a variety of ways, and their categorisation also varies.

For the purposes of this article such treatments will be referred to as 'non-mainstream'. Other descriptive terms for non-mainstream are 'complementary and/ or complementary medicine' referring to a broad set of healthcare practices that are not part of that country's own tradition or conventional medicine and not fully integrated into the dominant healthcare system. ${ }^{13}$ The term 'integrative' is used when conventional and complementary approaches are used in a coordinated way (https://nccih.nih.gov). Treatments move from non-mainstream to mainstream as their evidence base and/or acceptability grows.

Non-mainstream treatments are also described as 'natural'. Although doctors can be uncomfortable recommending treatments about which they are unknowledgeable and untrained, ${ }^{15}$ there is a growing interest in using natural medicines particularly in paediatrics. $^{1617}$

Carer use of non-mainstream treatments for ADHD has been found to be driven by a desire for alternatives to pharmaceutical medications, ${ }^{17-19}$; to minimise symptoms of ADHD; for additional benefit combined with conventional treatment; to avoid prescribed medication side effects, ${ }^{2021}$ and dissatisfaction with conventional care. ${ }^{22}$ Ninety per cent + carers of children with ADHD surveyed hope to see more research on non-mainstream treatments conducted. ${ }^{23}$

Surveys in several countries have sought to identify which and how frequently non-mainstream treatments are used to manage ADHD. Using Google Scholar, Web of Science and cross-referencing, 10 such surveys were found: three in Australia, five in the USA, one in Canada and one in Israel (table 1). No surveys were identified in the UK. This survey seeks to address this gap. Data about resource use was collected from a convenience sample of families recruited to the Sheffield Treatments for ADHD Research (STAR) project. The project used Trials within Cohorts (TwiCs) methodology, ${ }^{24}$ whereby first a large observational cohort of participants with the condition of interest was recruited and their outcomes of interest regularly measured.

This report describes the resource use reported by cohort participants at entry into the observational cohort (online supplemental appendix 1) ${ }^{25}$ Results of the pilot randomised controlled trials (RCTs) conducted within the cohort and detailed population characteristics are reported elsewhere. ${ }^{26}$

\section{Patient and public involvement}

The STAR project was preceded by a case series. ${ }^{27}$ Families with children with ADHD participating in this preceding study expressed frustration at the lack of helpful treatment options and a desire to support research testing new treatments which might help their children. These families contributed to the design of the STAR project including: the design and piloting of the study questionnaire where an extra open-ended question 'use this space for anything else you would like to tell us' was added (see online supplemental appendix 1); and the generation of an interactive hip-hop rap performance called Lost Voices based on participating family's stories, which was widely shared on Facebook and helped increase recruitment. ${ }^{28}$

\section{METHODS \\ Objective}

To describe what families in the UK are using to manage their children with ADHD.

\section{Approvals}

The STAR project (including the survey) was sponsored by the University of Sheffield (URMS number 143647), and approved under the University of Sheffield's Ethics Review Procedure by the School of Health and Related Research (ScHARR) Research Ethics committee (REC) on $30 / 4 / 15$, application number $003424^{25}$ Informed consent was received from all carers and children.

\section{Study design}

This survey reports the responses from UK families with children with ADHD who agreed to participate in an observational cohort. ${ }^{25} 26$

\section{Recruitment}

Families of children aged 5-18 with ADHD were recruited from a broad variety of non-NHS, non-treatment seeking settings, initially in Sheffield and then throughout the UK, between September 2015 and September 2016. These included local authority organisations, schools, ADHD and autism support groups, conferences, and social media.

Recruitment was via a questionnaire which could be completed on-line or on paper by carers and took approximately $10 \mathrm{~min}$ to complete (online supplemental appendix 1). Carers were asked to provide the date, address and name of the doctor who diagnosed the child's ADHD and complete the Conners Global ADHD Index (CGI) ${ }^{29}$ To be included in the cohort children were required to have a CGI T score of at least 55 (denoting mild a-typicality). No restriction was placed on length of time since diagnosis.

Carers were asked questions intended to capture all treatments ever received by the child, not specifically for their ADHD: ' Please tell us about all your child's diagnoses and any medications taken for them'; 'how often 


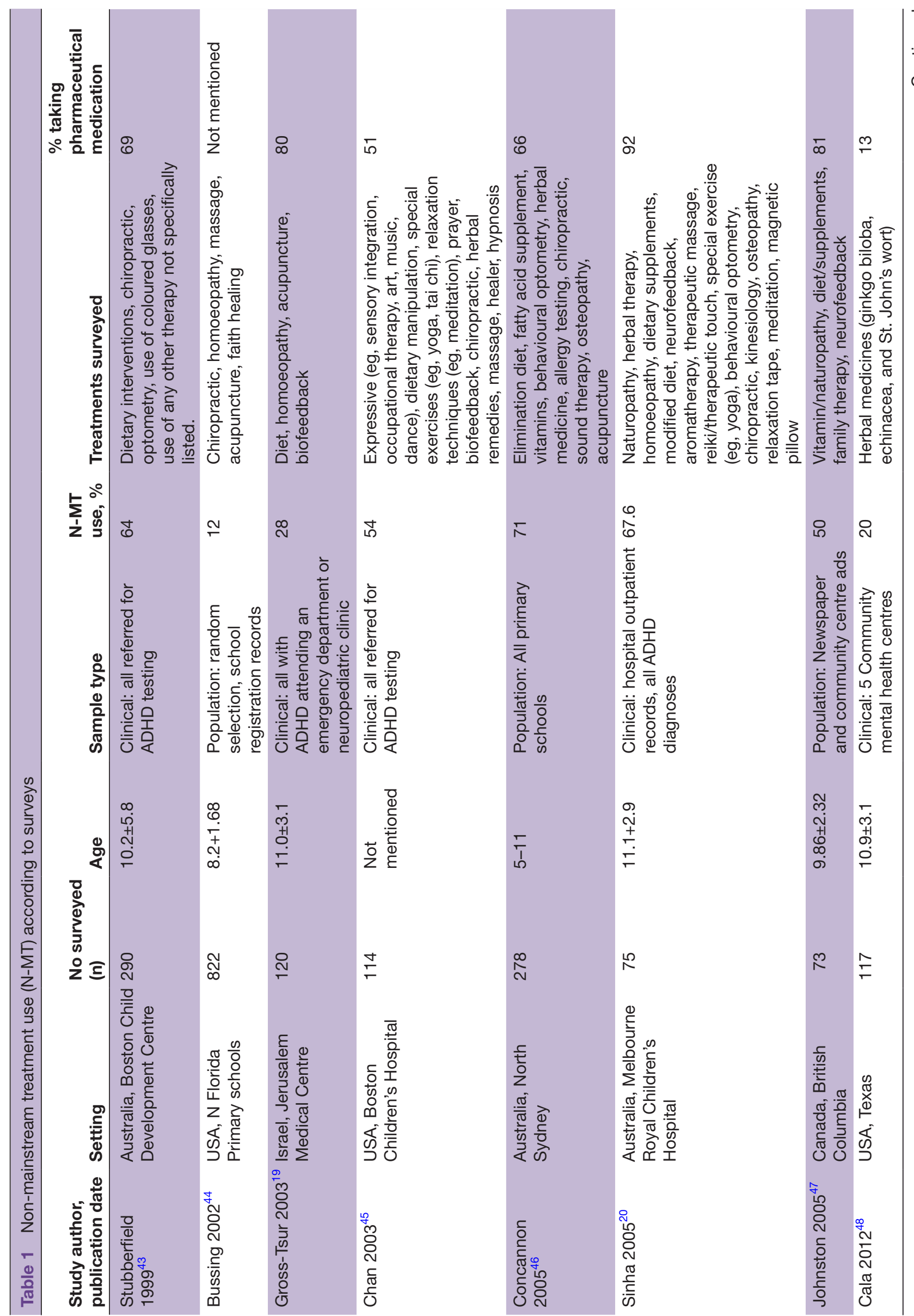




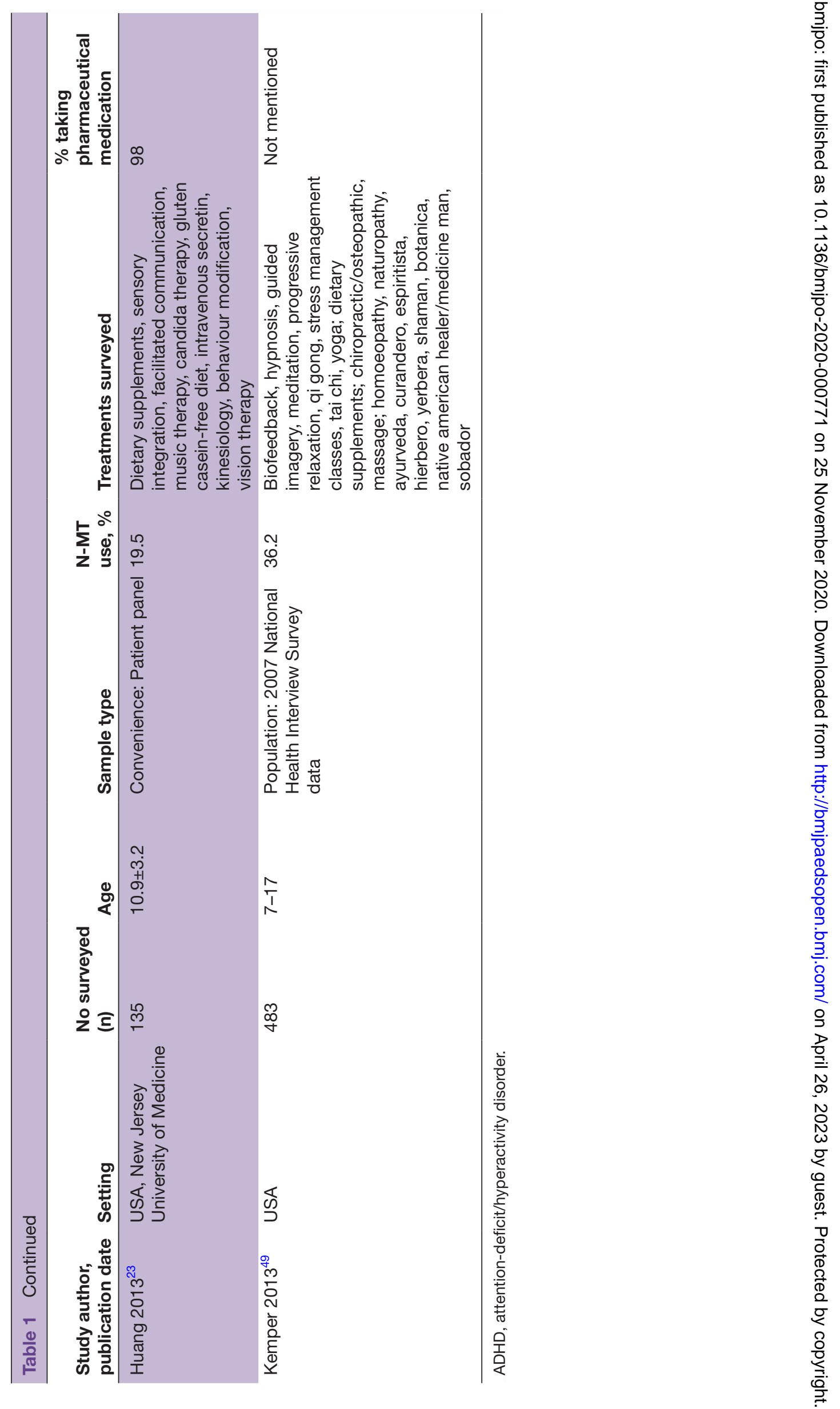


Table 2 Diagnoses of cohort participants

\begin{tabular}{lll}
\hline Diagnosis & $\begin{array}{l}\text { Numbers with } \\
\text { this diagnosis } \\
\text { (n) }\end{array}$ \\
\hline Additional & Sole diagnosis of ADHD & 61 \\
& Autism spectrum condition & 54 \\
& Anxiety & 14 \\
A learning difficulty & 14 \\
Asthma & 13 \\
Dyspraxia & 12 \\
Dyslexia & 11 \\
A sensory processing disorder & 11 \\
Oppositional defiant disorder & 8 \\
Tourette's syndrome & 7
\end{tabular}

ADHD, attention-deficit/hyperactivity disorder.

have you visited/been visited by the doctor, hospital, social worker or police in the last 6 months'; 'what else have you used to help your child in the past/now?: Family Action Parenting class (asked about on specific request from Sheffield Family Action); another parenting class? sessions with a psychologist?'; homoeopathy?'; (asked about due to inclusion/exclusion criteria for a subsequent RCT); anything else?'. This open-ended 'anything else' question was included to help identify all nonmainstream treatments that were or had been used. The final open-ended question 'use this space for anything else you would like to tell us' was included on patient and public involvement recommendation.

\section{RESULTS}

\section{Participant characteristics}

Questionnaires were completed by the carers of 194 children. Nineteen of these children had no reported diagnosis of ADHD, so their responses were excluded, therefore, the total number of children included in the survey was 175 .

Approximately one-third $(35 \%)$ reported a sole diagnosis of $\mathrm{ADHD}$, while the remaining two-thirds $(65 \%)$ reported one or more additional diagnoses of which the most common was an ASC (table 2).

The mean age of the children was 10.21 (2.44). Eightyfour per cent were boys and sixteen per cent girls. During the previous 6 months, 12 children had been involved with the police (range 1-20 visits per child). Fifteen children were involved with social workers (range 1-15 visits). Over half ( $\mathrm{n}=104)$ had visited hospital (range 1-20 visits) and had visited doctors $(\mathrm{n}=117)$ (range $1-20$ visits). Over half $(56 \%)$ of children had a teaching assistant, of whom $22 \%$ had one full time.

\section{Resource use}

Nearly two-thirds of the children were taking a mainstream ADHD medication, of which most took a
Table 3 Pharmaceutical medicines used by families

Total no Name of medication

(n), (\%) (no using)

\begin{tabular}{|c|c|c|}
\hline Category & (n), (\%) & (no using) \\
\hline $\begin{array}{l}\text { Medication for } \\
\text { core ADHD } \\
\text { symptoms }\end{array}$ & $120(69)$ & $\begin{array}{l}\text { Methylphenidate (103) } \\
\text { Amphetamine (9) } \\
\text { Atomoxetine (7) } \\
\text { Clonidine (1) }\end{array}$ \\
\hline $\begin{array}{l}\text { Medication } \\
\text { for associated } \\
\text { symptoms }\end{array}$ & $54(31)$ & $\begin{array}{l}\text { Sleep (melatonin) (49) } \\
\text { Antidepressant (sertraline, } \\
\text { prozac) (4) } \\
\text { Sedative (alimemazine) (1) }\end{array}$ \\
\hline
\end{tabular}

ADHD, attention-deficit/hyperactivity disorder.

methylphenidate derivative such as Ritalin. Nearly onethird took sleep medications (table 3).

One-third of families had participated in behaviour focused therapies (range 1-5 therapies per family) (table 4). The most frequently reported was consultation with a psychologist. Just under three quarters had participated in or were currently participating in parenting classes. Family Action is offered to all newly diagnosed families in Sheffield. Other classes mentioned were: 123 magic, triple $\mathrm{P}$, positive parenting, teach, change 4 life, anger management and incredible years.

Carers also described a wide variety of other creative and talking therapies that they used to help modify or manage behaviour. For example, art therapy, which was being offered by Sheffield Child and Adult Mental Health Services at the time.

A broad variety of activities ranging from the more physical such as judo, to the more creative such as theatre school, were described (range 1-4 activities per child). Seventeen families reported using aids, were which were usually to help the child with an accompanying ASC diagnosis (ear defenders and weighted blankets); or if hyperactivity and lack of focus were the issue (fiddle toys and wobble cushions) (table 4).

\section{Non-mainstream resource use}

Nearly half $(45 \%, \mathrm{n}=78)$ reported non-mainstream resource use (range $1-5$ per family), of which the most commonly reported was homoeopathy. The next most commonly reported was a dietary intervention: either taking an over the counter nutritional supplement, or diet changes, mostly without the support of a nutritional specialist (table 5).

There were responses from 61 participants to the openended question 'use this space for anything else you would like to tell us'. Their free text comments were thematically analysed. Six categories emerged: friendships, school, home, family circumstances, medication and sleep.

Carers described how lack of friendships were an issue for their children: 'My child gets excluded from parties, invitations to friend's houses and parents actively try to keep their children away'. School was problematic for both children and their carers trying to help them: 'today he didn't get up until I physically made him, he then missed his bus to school and then had an argument with other students 


\begin{tabular}{|c|c|c|c|}
\hline Category & Total no (n), (\%) & Question type & Name (no using) \\
\hline Parenting class & $130(74)$ & Specific & $\begin{array}{l}\text { Family action parenting class (55) } \\
\text { Another parenting class (75) }\end{array}$ \\
\hline \multirow[t]{2}{*}{ Behaviour-focused therapy } & $115(66)$ & Specific & Psychologist (83) \\
\hline & & Open & $\begin{array}{l}\text { Art therapy (5) } \\
\text { Play therapy (6) } \\
\text { Cognitive-behavioural therapy (5) } \\
\text { Counselling (5) } \\
\text { Psychotherapy (4) } \\
\text { Occupational therapy (3) } \\
\text { Sensory therapy (2) } \\
\text { Physiotherapy (1) } \\
\text { Family therapy (1) }\end{array}$ \\
\hline Aids (physical/visual/audial/behavioural) & $17(9)$ & Open & $\begin{array}{l}\text { Reward charts (7) } \\
\text { Fiddle toys, wobble cushions (3) } \\
\text { Quiet tent/time out space/ear defenders (3) } \\
\text { Relaxation CDs/baths (2) } \\
\text { Weighted blankets (2) }\end{array}$ \\
\hline Activities & $14(8)$ & Open & $\begin{array}{l}\text { Horse riding (2) } \\
\text { Swimming (2) } \\
\text { Cycling (1) } \\
\text { Duke of Edinburgh (1) } \\
\text { Gymnastics (1) } \\
\text { Judo (1) } \\
\text { Pilates (1) } \\
\text { Running club (1) } \\
\text { Scouts/beavers (1) } \\
\text { Tae kwon do (1) } \\
\text { Theatre school (1) } \\
\text { Trampoline (1) }\end{array}$ \\
\hline
\end{tabular}

during lunch break. When finally I got him organised to sit down and do some homework it turned out he'd lost it on the way home. Quite a typical day!'.
Home life was described as stressful, particularly in the mornings: 'Home life very much affected by $\mathrm{X}$ to the point of being ruled by her behaviour.... still not dressed today

\begin{tabular}{|c|c|c|c|}
\hline Category & Total no used & Question type & Name (number using) \\
\hline Nutritional & 21 & Open & $\begin{array}{l}\text { Fish oils (9) } \\
\text { Dietary changes (restricting foods/Feingold diet/healthy diet) (7) } \\
\text { Dietician/nutritionist/nutritional therapy (3) } \\
\text { Other supplements (2) }\end{array}$ \\
\hline Bodywork & 9 & Open & $\begin{array}{l}\text { Massage (5) } \\
\text { Cranial osteopathy (4) }\end{array}$ \\
\hline Other & 48 & $\begin{array}{l}\text { Specific } \\
\text { Open }\end{array}$ & $\begin{array}{l}\text { Homoeopathy (32) } \\
\text { Aromatherapy (2) } \\
\text { Crystals (2) } \\
\text { Hypnotherapy (2) } \\
\text { Reiki (2) } \\
\text { Acupuncture (1) } \\
\text { Bach flower remedies (1) } \\
\text { Cannabidiol oil (1) } \\
\text { Epsom salts (1) } \\
\text { Meditation (2) } \\
\text { Metamorphic technique (1) } \\
\text { Reflexology (1) }\end{array}$ \\
\hline
\end{tabular}


at $5 \mathrm{pm}$ despite numerous prompts'. Family circumstances described were specific traumas and bereavements: ' $\mathrm{X}$ was removed from birth mum at birth, was in foster care until 17 months old when she was placed with us'.

Medication experiences were both positive: 'The medication is an absolute God send. Without it our lives would be so stressful and I'm sure X wouldn't be able to attend mainstream school'; and negative 'can't take any due to bad reaction on her stomach, tried 5 different ones'. Sleep problems were commonly mentioned: 'Last night was a good night's sleep for my son and he slept till after 6 . This is a rarity as he can be awake and hyperactive from 2am.'. Many felt that ADHD is mis-understood and that the voices of families with ADHD not heard.

\section{DISCUSSION}

The number of families reporting that their children had codiagnoses suggest that in this regard, this convenience sample are broadly representative of the ADHD population, where co-diagnoses are estimated to occur in $40 \%-65 \% .^{3031}$

This survey reports high levels of health need and use of public resources. The majority of those surveyed used mainstream treatments such as pharmaceutical medications, behaviour management classes and psychological therapies. Seven per cent of families were involved with social workers; $6 \%$ of children had been excluded from school and 5\% were currently, or had been involved with the police. Additionally, $45 \%$ of families had used nonmainstream treatments.

The most commonly used non-mainstream treatments were homoeopathy and nutrition. The role of nutrition is increasingly acknowledged in the aetiology, impact on, and treatment of, ADHD. Consideration of nutrition is now moving towards the mainstream, as exemplified by its recent inclusion in NICE guidelines. More surprising is the high use of homoeopathy. It is unclear whether use refers to over the counter homeopathic medicines such as Arnica for bruising, or Chamomilla for teething, or visits to a homeopath (available via the NHS in some parts of the UK), or both.

Sample sizes of surveys conducted in other countries range from 73 to 822 . Ours was 175 . At $31 \%$, our nonmainstream treatment use is slightly less than median usage found in other surveys (range 12\%-71\%) (table 1). Lower estimates are thought to be the result of narrower definitions of such treatments, ${ }^{1932}$ however, our inclusion of an open-ended question theoretically allowed for broad definition of non-mainstream treatments, and indeed included a diverse array. Reported use appears to vary by country, with higher use reported in Australia (range 64\%-71\%) and lower use in the USA (range 12\%-54\%). Surveys agree that treatments are predominantly used alongside pharmaceutical medications (table 1 ).

The results of our survey broadly concur with those from other surveys. Although other surveys varied in the non-mainstream treatments they asked about, they commonly asked about dietary interventions $(8 / 10)$, with some asking generally, and some specifically about supplements and dietary changes. Four surveys asked about herbs, homoeopathy or chiropractic/osteopathy; and three about acupuncture or yoga. According to the 10 surveys, the most popular treatments were supplements, dietary changes, acupuncture, homoeopathy, massage, craniosacral therapy, music therapy, equine therapy, secretin and chelation.

Popular treatments according to our survey were homoeopathy, nutrition (particularly supplementary fish oils), massage, osteopathy, aromatherapy, a variety of relaxation approaches, acupuncture and hypnotherapy. However, none in our survey reported using herbs. Unique to our survey was reported use of Cannabidiol oil, Epsom salts, metamorphic technique, reflexology, crystals and Bach flower remedies.

A limitation of our survey is the mixture of questions specifying a particular intervention (eg, have you done a parenting class/seen a psychologist/used homoeopathy) and more open questions (eg, what else have you done to help your child). There are advantages and disadvantages of each question type: the use of an open-ended question allowed the broad spectrum of treatments being used to be represented; however, it is likely that some utilised treatments were omitted which might have been remembered had a prompt list been provided.

Most interventions being used are under researched and the evidence produced low quality due to: poor internal validity (lack of blinded assessment, and small population sizes); poor external validity (lack of trials in representative populations and lack of measurement of long-term outcomes); and poor ecological validity (tested interventions do not represent core aspects of the therapy). In 2000, it was identified as a public health issue in the UK that we do not have adequate knowledge of the putative benefits of non-mainstream treatments. ${ }^{33} \mathrm{We}$ still have little information and just $0.0085 \%$ of research funding is allocated to testing Complementary and Alternative Medicine interventions in the UK. ${ }^{34}$

Of the treatments used, elements of a nutritional approach are the most researched, particularly the 'few foods diet', artificial food colour elimination, fatty acid supplementation, single and multiple nutrients. Effect sizes are generally small. Researchers concur that the few foods diet may offer opportunities, but further large-scale, high-quality studies are needed. ${ }^{35}$ It is unlikely that single nutrient or dietary interventions impact the complex array of biochemical pathways that may be aberrant in ADHD. Furthermore administration of one nutrient or approach may cause an imbalance in another. ${ }^{7}$ The pilot RCT conducted in our cohort tested the effectiveness of offering a total nutritional approach combining supplementation, elimination, and healthy diet advice by a nutritional therapist. ${ }^{26} \mathrm{~A}$ medium effect size was found, and the pragmatic trial design used may address some of these issues. 
Homoeopathy is the next most researched treatment. Three RCTs testing the efficacy of individually tailored homoeopathic medicines, ${ }^{36-38}$ and one testing the efficacy of a generic homeopathic product, ${ }^{39}$ were synthesised in a Cochrane review ${ }^{40}$ which overall found little evidence of efficacy and recommended development of optimal treatment protocols. Subsequently, two further RCTs testing the effectiveness of treatment by homoeopaths, ${ }^{26}{ }^{41}$ and one testing the efficacy of a generic homeopathic product, ${ }^{42}$ have been conducted.

Families used their experience of participating in an observational cohort to describe a broad variety of resources and treatments they use to manage the condition over and above NHS recommended treatments. This is a convenience sample of participants in the UK who consented to recruit to a cohort, and it may be that dissatisfaction with conventional care drew them towards participation. Nevertheless, results from our survey do not deviate substantially from the results from population and clinical samples.

\section{CONCLUSION}

Development of robust evidence of the putative effectiveness of the non-mainstream treatments being used should be a priority given that they are being used by carers; paediatric doctors are increasingly turning to more natural treatments; long-term negative outcomes of those with ADHD are not being affected; and currently recommended treatments are palliative and associated with common side effects. Surveying carers is a useful means of identifying which treatments are being used and should subsequently be tested.

Acknowledgements The work could not have been conducted without the support of all the participating families with children with ADHD.

Contributors PF planned, conducted and analysed the survey and wrote the manuscript. CR helped design the research methodology and edit the manuscript.

Funding This work was supported by the Homeopathic Research Institute (Company Registration number 06230101; Charity Registration number 1132901), who had no role in the design, collection or analysis of data.

Competing interests None declared.

Patient consent for publication Not required.

Provenance and peer review Not commissioned; externally peer reviewed.

Data availability statement Data are available on reasonable request. Data are stored using facilities provided by Google. Arrangement provided under contract with the University of Sheffield.

Supplemental material This content has been supplied by the author(s). It has not been vetted by BMJ Publishing Group Limited (BMJ) and may not have been peer-reviewed. Any opinions or recommendations discussed are solely those of the author(s) and are not endorsed by BMJ. BMJ disclaims all liability and responsibility arising from any reliance placed on the content. Where the content includes any translated material, BMJ does not warrant the accuracy and reliability of the translations (including but not limited to local regulations, clinical guidelines, terminology, drug names and drug dosages), and is not responsible for any error and/or omissions arising from translation and adaptation or otherwise.

Open access This is an open access article distributed in accordance with the Creative Commons Attribution Non Commercial (CC BY-NC 4.0) license, which permits others to distribute, remix, adapt, build upon this work non-commercially, and license their derivative works on different terms, provided the original work is properly cited, appropriate credit is given, any changes made indicated, and the use is non-commercial. See: http://creativecommons.org/licenses/by-nc/4.0/.
ORCID iD

Philippa Fibert http://orcid.org/0000-0001-5364-6022

\section{REFERENCES}

1 Peasgood T, Bhardwaj A, Biggs K, et al. The impact of ADHD on the health and well-being of ADHD children and their siblings. Eur Child Adolesc Psychiatry 2016;25:1217-31.

2 Harpin VA. The effect of ADHD on the life of an individual, their family, and community from preschool to adult life. Arch Dis Child 2005;90 Suppl 1:i2-7.

3 Ronald A, Simonoff E, Kuntsi J, et al. Evidence for overlapping genetic influences on autistic and ADHD behaviours in a community twin sample. J Child Psychol Psychiatry 2008;49:535-42.

4 Storebø OJ, Ramstad E, Krogh HB, et al. Methylphenidate for children and adolescents with attention deficit hyperactivity disorder (ADHD). Cochrane Database Syst Rev 2015;48.

5 Owens JA. Sleep disorders and attention-deficit/hyperactivity disorder. Curr Psychiatry Rep 2008;10:439-44.

6 Gillberg C, Gillberg IC, Rasmussen P, et al. Co-existing disorders in ADHD -- implications for diagnosis and intervention. Eur Child Adolesc Psychiatry 2004;13(Suppl 1):i80-92.

7 Rucklidge JJ, Johnstone JM. The role of diet and nutrient supplementation in the treatment of ADHD. ADHD Rep 2016;24:1-8.

8 Cortese S, Moreira-Maia CR, St Fleur D, et al. Association between ADHD and obesity: a systematic review and meta-analysis. Am J Psychiatry 2016;173:34-43.

9 Mayes SD, Calhoun SL, Bixler EO, et al. ADHD subtypes and comorbid anxiety, depression, and oppositional-defiant disorder: differences in sleep problems. J Pediatr Psychol 2009;34:328-37.

10 DuPaul GJ, Weyandt LL. School-based intervention for children with attention deficit hyperactivity disorder: effects on academic, social, and behavioural functioning. Int J Disabil Dev Educ 2006;53:161-76.

11 Tarver J, Daley D, Sayal K, et al. Attention-deficit hyperactivity disorder (ADHD): an updated review of the essential facts. Child Care Health Dev 2014;40:762-74.

12 Swanson JM, Arnold LE, Molina BSG, et al. Young adult outcomes in the follow-up of the multimodal treatment study of attention-deficit/ hyperactivity disorder: symptom persistence, source discrepancy, and height suppression. J Child Psychol Psychiatry 2017;58:663-78.

13 World Health Organization. Who traditional medicine strategy 20142023. Geneva, Switzerland: World Health Organization, 2013.

14 Huckstadt MR, Beer AM, Burlaka I, et al. P319 attitude towards paediatric use of natural medicines: a cross-country survey conducted in general paediatrics. Arch Dis Child 2017;102:A156-7.

15 Akins RS, Angkustsiri K, Hansen RL. Complementary and alternative medicine in autism: an evidence-based approach to negotiating safe and efficacious interventions with families. Neurotherapeutics 2010;7:307-19.

16 Beer A-M, Burlaka I, Buskin S, et al. Usage and attitudes towards natural remedies and Homeopathy in general pediatrics: a CrossCountry overview. Glob Pediatr Health 2016;3:2333794X1562540.

17 Baumgaertel A. Alternative and controversial treatments for attention-deficit/hyperactivity disorder. Pediatr Clin North Am 1999;46:977-92.

18 Brue AW, Oakland TD. Alternative treatments for attention-deficit/ hyperactivity disorder: does evidence support their use? Altern Ther Health Med 2002;8:68.

19 Gross-Tsur V, Lahad A, Shalev RS. Use of complementary medicine in children with attention deficit hyperactivity disorder and epilepsy. Pediatr Neurol 2003;29:53-5.

20 Sinha D, Efron D. Complementary and alternative medicine use in children with attention deficit hyperactivity disorder. J Paediatr Child Health 2005;41:23-6.

21 Hanson E, Kalish LA, Bunce E, et al. Use of complementary and alternative medicine among children diagnosed with autism spectrum disorder. J Autism Dev Disord 2007;37:628-36.

22 Bishop FL, Yardley L, Lewith GT. A systematic review of beliefs involved in the use of complementary and alternative medicine. $J$ Health Psychol 2007;12:851-67.

23 Huang A, Seshadri K, Matthews TA, et al. Parental perspectives on use, benefits, and physician knowledge of complementary and alternative medicine in children with autistic disorder and attention-deficit/hyperactivity disorder. J Altern Complement Med 2013;19:746-50.

24 Relton C, Torgerson D, O'Cathain A, et al. Rethinking pragmatic randomised controlled trials: introducing the "cohort multiple randomised controlled trial" design. BMJ 2010;340:c1066.

25 Fibert P, Relton C, Peasgood T, et al. Protocol for the STAR (Sheffield treatments for ADHD) project: an internal pilot study assessing the feasibility of the trials within cohorts (TwiCs) design to test the 
effectiveness of interventions for children with ADHD. Pilot Feasibility Stud 2018:4:61.

26 Fibert P, Peasgood T, Relton C. Rethinking ADHD intervention trials: feasibility testing of two treatments and a methodology. Eur $J$ Pediatr 2019;178:983-93.

27 Fibert P, Relton C, Heirs M, et al. A comparative consecutive case series of 20 children with a diagnosis of ADHD receiving homeopathic treatment, compared with 10 children receiving usual care. Homeopathy 2016;105:194-201.

28 Available: https://www.facebook.com/starsheffieldADHD/videos/ 677387002419685/

29 Conners C. Conners 3rd edition manual. USA: Multi Health Systems Inc, 2009.

30 Jensen PJ, Arnold LE, Richters JE, et al. Moderators and mediators of treatment response for children with attention-deficit/hyperactivity disorder: the multimodal treatment study of children with attentiondeficit/hyperactivity disorder. Arch Gen Psychiatry 1999;56:1088-96.

31 Punja S, Shamseer L, Hartling L, et al. Amphetamines for attention deficit hyperactivity disorder (ADHD) in children and adolescents. Cochrane Database Syst Rev 2016;2:CD009996.

32 Weber W, Newmark S. Complementary and alternative medical therapies for attention-deficit/hyperactivity disorder and autism. Pediatr Clin North Am 2007;54:983-1006.

33 House of Lords Select Committee on Science and Technology. Report on complementary and alternative medicine. London: Stationary Office, 2000.

34 Lewith GT. Funding for CAM. BMJ 2007;335:951.

35 Stevenson J, Buitelaar J, Cortese S, et al. Research review: the role of diet in the treatment of attention-deficit/hyperactivity disorder-an appraisal of the evidence on efficacy and recommendations on the design of future studies. J Child Psychol Psychiatry 2014;55:416-27.

36 Frei H, Everts R, von Ammon K, et al. Homeopathic treatment of children with attention deficit hyperactivity disorder: a randomised, double blind, placebo controlled crossover trial. Eur J Pediatr 2005;164:758-67.

37 Jacobs J, Williams A-L, Girard C, et al. Homeopathy for attentiondeficit/hyperactivity disorder: a pilot randomized-controlled trial. J Altern Complement Med 2005;11:799-806.
38 Lamont J. Homoeopathic treatment of attention deficit hyperactivity disorder. Br Homeopath J 1997;86:196-200.

39 Strauss LC, intern $\mathrm{H}$. The efficacy of a homeopathic preparation in the management of attention deficit hyperactivity disorder. Biomed Ther 2000;18:197-201.

40 Heirs M, Dean ME, Cochrane Developmental, Psychosocial and Learning Problems Group. Homeopathy for attention deficit/ hyperactivity disorder or hyperkinetic disorder. Cochrane Database Syst Rev 2007;164.

41 Oberai P, Gopinadhan S, Varanasi R, et al. Homoeopathic management of attention deficit hyperactivity disorder: a randomised placebo-controlled pilot trial. Ind J Res Homoeopathy 2013;7:158-67.

42 Razlog R, Pellow J, White SJ. A pilot study on the efficacy of Valeriana officinalis mother tincture and Valeriana officinalis $3 X$ in the treatment of attention deficit hyperactivity disorder. Health $S A$ Gesondheid 2012;17:1-7.

43 Stubberfield T, Parry T. Utilization of alternative therapies in attention-deficit hyperactivity disorder. J Paediatr Child Health 1999;35:450-3.

44 Bussing R, Zima BT, Gary FA, et al. Use of complementary and alternative medicine for symptoms of attention-deficit hyperactivity disorder. Psychiatr Serv 2002;53:1096-102.

45 Chan E, Rappaport LA, Kemper KJ. Complementary and alternative therapies in childhood attention and hyperactivity problems. $J$ Dev Behav Pediatr 2003:24:4-8.

46 Concannon PE, Tang YP. Management of attention deficit hyperactivity disorder: a parental perspective. J Paediatr Child Health 2005:41:625-30.

47 Johnston C, Seipp C, Hommersen P, et al. Treatment choices and experiences in attention deficit and hyperactivity disorder: relations to parents' beliefs and attributions. Child Care Health Dev 2005;31:669-77.

48 Cala S, Crismon ML, Baumgartner J. A survey of herbal use in children with attention-deficit-hyperactivity disorder or depression. Pharmacotherapy 2003;23:222-30.

49 Kemper KJ, Gardiner P, Birdee GS. Use of complementary and alternative medical therapies among youth with mental health concerns. Acad Pediatr 2013;13:540-5. 